\title{
The effect of lockdown regulations on SARS-CoV-2 infectivity in Gauteng Province, South Africa
}

\author{
J Pillai, ${ }^{1}$ FCS CVS (SA); P Motloba, ${ }^{2}$ MDent; K S C Motaung, ${ }^{3,4}$ DTech; L U Ozougwu, ${ }^{1}$ MSc; B K Ikalafeng, ${ }^{5}$ DCur; \\ E Marinda, ${ }^{6,7} \mathrm{PhD}$; M Lukhele, ${ }^{5}$ MMed (Orth), FCS (SA) (Orth); D Basu, ${ }^{8,9}$ FCPHM, PhD (Med) \\ ${ }^{1}$ Department of Surgery, Faculty of Health Sciences, University of the Witwatersrand, Johannesburg, South Africa \\ ${ }^{2}$ Department of Community Dentistry, School of Oral Health Sciences, Sefako Makgatho Health Sciences University, Pretoria, South Africa \\ ${ }^{3}$ Department of Biomedical Sciences, Faculty of Science, Tshwane University of Technology, Pretoria, South Africa \\ ${ }^{4}$ Department of Technology Transfer and Innovation, Durban University of Technology, Durban, South Africa \\ ${ }^{5}$ Gauteng Department of Health, Johannesburg, South Africa \\ ${ }^{6}$ Human Sciences Research Council, Pretoria, South Africa \\ ${ }^{7}$ School of Public Health, Faculty of Health Sciences, University of the Witwatersrand, Johannesburg, South Africa \\ ${ }^{8}$ Department of Public Health Medicine, Steve Biko Academic Hospital and Faculty of Health Sciences, University of Pretoria, South Africa \\ ${ }^{9}$ World Health Organization Collaborating Centre for Social Determinants of Health and Health in All Policies, Pretoria, South Africa
}

Corresponding author: D Basu (debashis.basu@up.ac.za)

Background. On 26 March 2020, the South African (SA) government initiated a 21-day national level 5 lockdown which was subsequently eased off and downgraded to level 4 on 1 May and to level 3 on 1 June. The effect of lockdown measures on SARS-CoV-2 infectivity is currently uncertain. In this article, we analyse the effects of the lockdown measures on the SARS-CoV-2 epidemic in one of the epicentres in SA.

Objectives. To measure the effects of lockdown measures introduced in SA on SARS-CoV-2 attack rates (ARs, the percentage of individuals who tested positive in a specified time period) in Gauteng Province during a 4-month period (March - June 2020).

Methods. In this retrospective cohort study, we used a comprehensive database from an independent pathology laboratory in Gauteng. We analysed trends of positivity rates of reverse transcription polymerase chain reaction tests done during the 4-month period. The ARs are reported over time (unweighted and age-weighted 14-day moving averages) by age groups, gender, and different regions/districts in Gauteng. Results. A total of 162528 tests were performed at a private laboratory between 5 March and 30 June 2020 , of which 20574 were positive (overall AR 12.7\%). These positive tests constituted $44.8 \%$ of all positive cases in the province (20 574/45 944). Sixty-two percent of all tests were done in June during lockdown level 3. There was an exponential increase in the AR in June (18.3\%) when lockdown was eased to level 3, in comparison with 4.2\% (March), 2.2\% (April) and 3.3\% (May). The increase in June was seen in all the age groups, although it was more pronounced in the 21 - 60 years age groups than the younger $(0-20$ years) and older ( $>60$ years) age groups. The AR was significantly higher in males $(13.2 \%)$ compared with females $(12.1 \%)\left(\chi^{2}\right.$ test, $\left.p<0.0001\right)$.

Conclusions. The findings of this study testify to the rapid increase in ARs resulting from easing of the lockdown regulations, especially to level 3 in June. Of concern is the upward trend in the AR across all age groups, especially $<20$ years (15.9\%), which was not reported in other parts of the world. Population age dynamics should therefore be considered when taking future decisions about lockdown regulations.

S Afr Med J 2020;110(11):1119-1123. https://doi.org/10.7196/SAMJ.2020.v110i11.15222

The rapid spread of COVID-19 has resulted in a global pandemic. ${ }^{[1]}$ By 10 July 2020, 22 million cases had been reported worldwide, resulting in 580000 deaths. Governments around the world have implemented variable lockdown regulations to curb the rapid transmission of SAR-CoV-2. The first South African (SA) case of COVID-19 was reported on 5 March. ${ }^{[2]}$ On 26 March, the SA government initiated a 21-day national level 5 lockdown. ${ }^{[3]}$ The strict regulations included restriction of population mobility and interaction, international and domestic travel restrictions, restriction of commercial and business activity, cancellation of events and gatherings, and closure of schools and universities. Essential services such as security, health and food distribution were permitted. ${ }^{[4]}$ The lockdown was eased off and downgraded to level 4 on 1 May and to level 3 on 1 June (Fig. 1). Many businesses were allowed to resume operations, and the regulations allowed for workers to resume work. By 1 July 2020, 159333 cases of COVID-19 had been reported in SA, 45944 (29\%) in Gauteng Province. ${ }^{[5]}$ Gauteng is the smallest province in SA, accounting for $1.5 \%$ of the land area, but it is the most densely populated province (accounting for $26 \%$ of the country's population) and is widely regarded as the country's economic and industrial powerhouse. ${ }^{[6]}$

The progression and impact of SARS-CoV-2 are dependent on the demography of specific geographical regions. While mortality is higher in the older age group, relaxation of strict lockdown regulations may affect the working age group because of their increased mobility. Knowledge of age-specific infectivity may therefore provide insights into the impact and future trends of SARS-CoV-2 that may assist in developing mitigation strategies to counteract viral transmission. The effect of lockdown measures on SARS-CoV-2 infectivity is currently unknown in SA. In this article, we analyse the effects of the lockdown measures initiated on 26 March 2020 on SARS-CoV-2 attack rates (ARs) in Gauteng during the first 4 months of the epidemic in SA. We also studied the effects of geographical region, gender and age on the AR.

\section{Methods}

In this retrospective cohort study, we used a comprehensive database from an independent pathology laboratory in Johannesburg, 
Gauteng, during a 4-month period (5 March 2020 - 30 June 2020). Reverse transcription polymerase chain reaction (RT-PCR) tests of both symptomatic and asymptomatic individuals $(N=162528)$ were analysed. Repeat tests from the same individuals were excluded. Although not exactly aligned with district boundaries, the central, east, north, south and west regions generally represent the Johannesburg, Ekurhuleni, Tshwane, Sedibeng and West Rand districts, respectively.

Data were transcribed into a worksheet by laboratory staff and then anonymised so that investigators were 'blinded' to patients' names and personal details. The data were stratified into region, gender and age groups $(0-10,11-20,21-30,31-40$, $41-50,51-60$ and $>60$ years).

The AR (the percentage of individuals who tested positive over a specified time period) was further analysed over four time periods: (i) pre-lockdown (5 - 31 March); (ii) lockdown level 5 (1 - 30 April); (iii) lockdown level 4 (1 - 31 May); and (iv) lockdown level 3 (1 - 30 June) (Fig. 1).

A logistic regression model with outcome testing, positive being 1 and negative being 0 , was fitted for time, age and gender. This was used for assessment of the effects of lockdown on the AR. The interactive association of age and gender, independently, was fitted with time to check whether there were differential infection rates. There was no interaction between gender and time, but there was an interaction between time and age. Logistic regression models were therefore performed for each of the age groups $0-20,21-60$ and $>60$ years. From a logistic regression model, we estimated differences associated with gender and the four time periods in each age group. We chose a 14-day interval for calculation of the moving average based on the infective period for SARS-CoV-2. Fourteen-day moving averages, unadjusted and adjusted for age and gender using the mid-year Gauteng population, were calculated and plotted against time.

\section{Results}

A total of 162528 tests were performed at the laboratory between 5 March and 30 June 2020. Of these, 20574 were positive (overall AR 12.7\%). These positive tests constituted $44.8 \%$ of all positive cases reported in the province (20 574/45 944). The numbers of tests performed during March, April, May and June were 12430 (7.6\%), 11384 (7.0\%), 37409 (23.1\%), and $101305(62.3 \%)$, respectively. There was a decrease during level 5 lockdown (April), followed by increases during level 4 (May) and level 3 (June).

Individuals in the age groups $31-40$ and 41 - 50 years had the highest number of tests done (27.5\% and $19.6 \%$, respectively). Individuals aged $<10$ years and $>60$ years had $4.5 \%$ and $11.6 \%$ of all tests, respectively (Fig. 2).

More females $(54.8 \%)$ than males were tested. The AR was significantly higher in males (13.2\%) compared with females $(12.1 \%)\left(\chi^{2}\right.$ test, $\left.p<0.0001\right)$.

\section{ARs over time}

The AR for different regions over the 4-month study period is described in Table 1. All regions showed a remarkable increase in ARs in June.

Owing to the interaction effect between age and time, we calculated separate ARs for each age group. There were differential increases in AR for all age groups over time (Table 2 and Fig. 3). For all individuals, the AR during pre-lockdown, level 5 lockdown, level 4 lockdown and level 3 lockdown was $4.1 \%, 2.2 \%, 3.4 \%$ and $18.5 \%$, respectively. There was a rapid increase in AR during level 3, when additional restrictions were lifted (Table 3).

For the age group $0-20$ years, the AR during pre-lockdown and levels 5, 4 and 3 lockdown was $3.5 \%, 1.0 \%, 2.7 \%$ and $15.9 \%$, respectively. A rapid increase in AR was noted in level 3. Relative to the pre-lockdown period, the odds of testing positive for this age group were $70 \%$ lower in level 4 (adjusted odds ratio (aOR) 0.3; 95\% confidence interval (CI) 0.15 - 0.61; $p<0.01$ ) and $21 \%$ lower in level 3 (aOR 0.79; $95 \%$ CI 0.53 - 1.18). In level 5 , the odds of infection were $427 \%$ higher compared with the pre-lockdown level.

For the age group 21 - 60 years, the AR during pre-lockdown and levels 5, 4 and 3 lockdown was $4.0 \%, 2.4 \%, 3.8 \%$ and $19.3 \%$, respectively. A rapid increase in AR was also noted in level 3. Relative to the prelockdown period, the aOR was $42 \%$ lower in

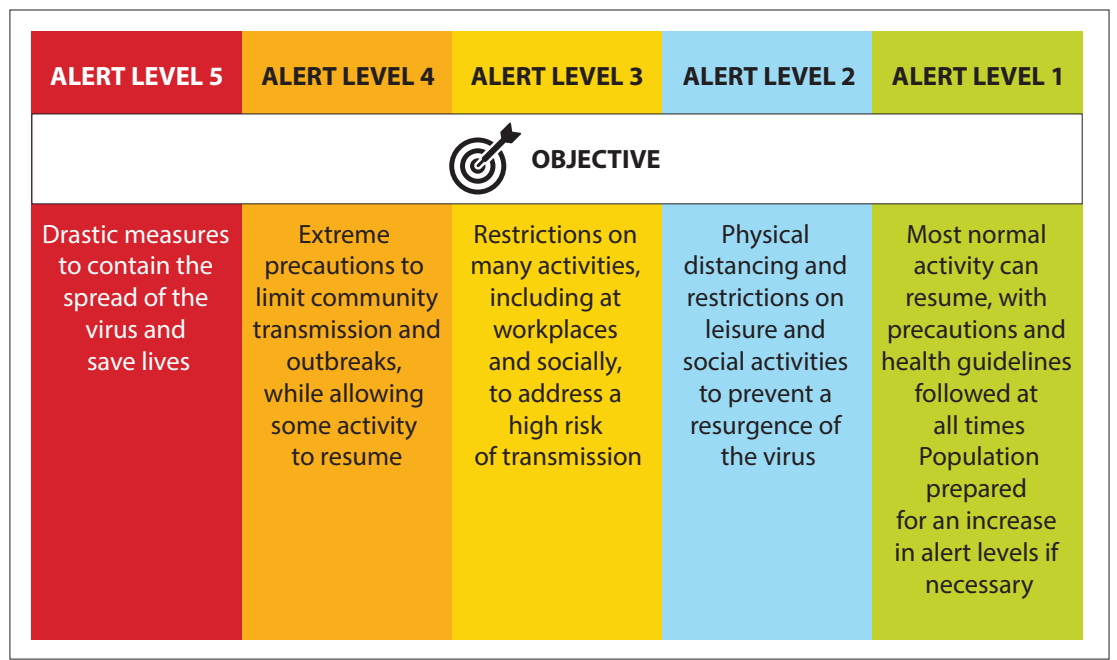

Fig. 1. Levels of lockdown in South Africa.

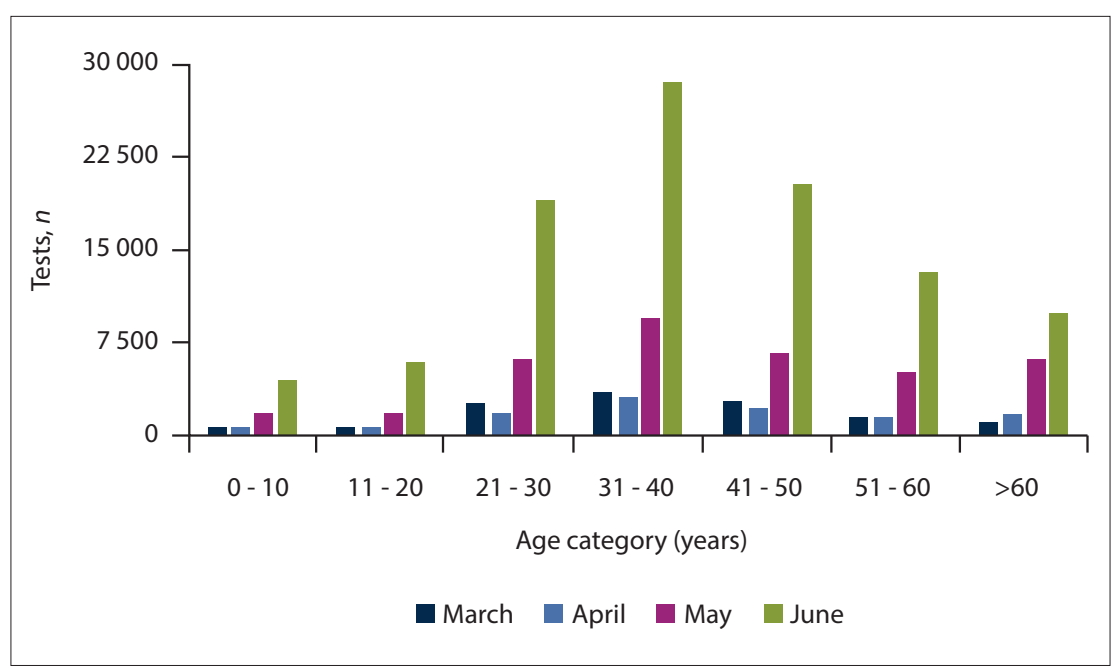

Fig. 2. Reverse transcriptase polymerase chain reaction tests in age categories. 
level 5, 2\% lower in level 4 and 469\% higher in level 3. In this age group, males had a 1.1 times (95\% CI 1.06 - 1.13) higher odds of testing positive compared with females.

For the age group $>60$ years, the $\mathrm{AR}$ during pre-lockdown and levels 5, 4 and 3 lockdown was $5.4 \%, 2.0 \%, 2.2 \%$ and $15.3 \%$, respectively. Again, a rapid increase in AR was noted for this age group in level 3 . Relative to the pre-lockdown period, the aOR for infection was $65 \%$ and $62 \%$ lower in level 5 and level 4, respectively, whereas it increased by $215 \%$ in level 3 .

In line with the above results, Fig. 3 shows that ARs decreased from pre-lockdown rates to a lower rate in level 5 (most restrictive period) and level 4 (when a number of essential services were allowed). The AR then increased sharply in level 3 (when many industries and schools reopened). The trends were similar when 14-day moving average ARs were weighted for age and gender (Fig. 4).

\begin{tabular}{|c|c|c|c|c|}
\hline Region & March & April & May & June \\
\hline Central (Johannesburg) & 4 & 3 & 5 & 20 \\
\hline East (Ekurhuleni) & 4 & 2 & 3 & 17 \\
\hline North (Tshwane) & 5 & 3 & 2 & 14 \\
\hline South (Sedibeng) & 3 & 1 & 3 & 21 \\
\hline West (West Rand) & 3 & 1 & 4 & 21 \\
\hline
\end{tabular}

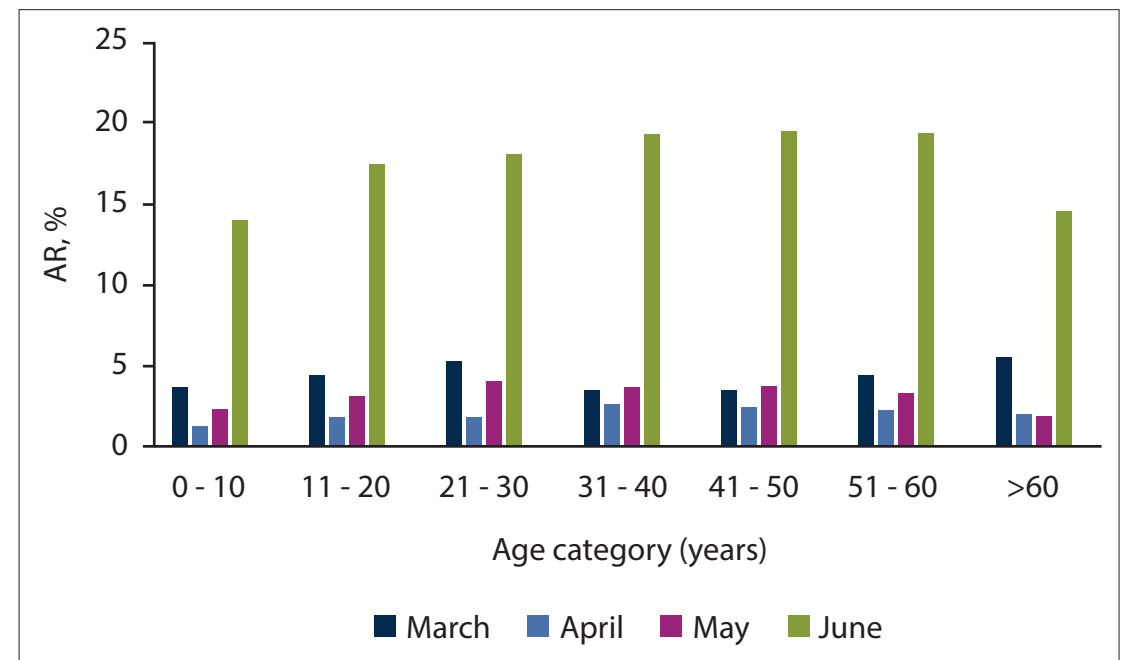

Fig. 3. AR in different age categories. $(A R=$ attack rate. $)$

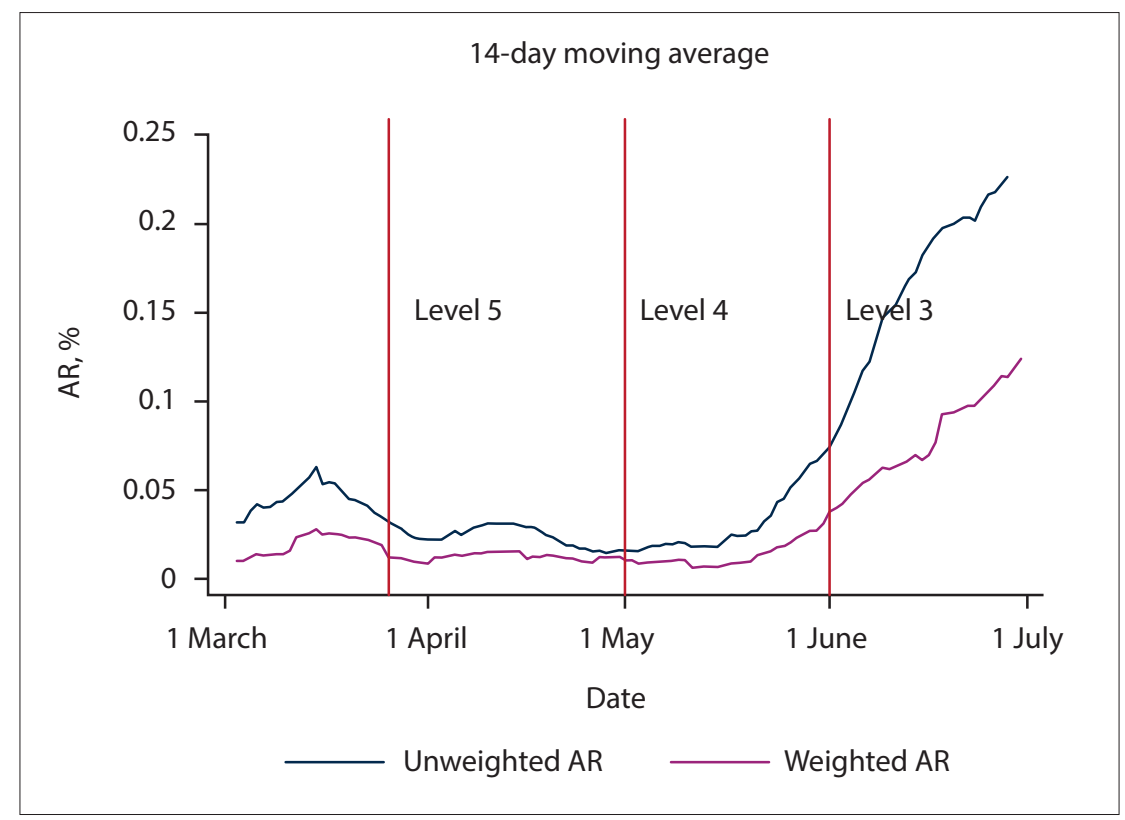

Fig. 4. AR during lockdown (unweighted and 14 days weighted for different age groups). $(A R=$ attack rate. $)$

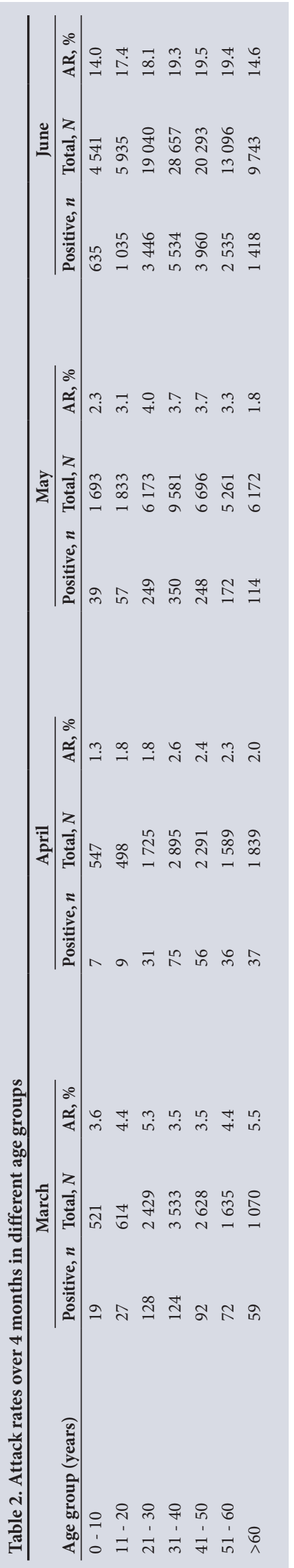


Table 3. Adjusted odds ratio for gender and age groups over the 4-month study period

\begin{tabular}{|c|c|c|c|c|}
\hline Age group (years) & Gender and month & AR, mean (SD) & aOR $(95 \% \mathrm{CI})$ & $p$-value \\
\hline \multirow[t]{8}{*}{$0-20$} & Sex & & & \\
\hline & Female & $11.39(6.4)$ & 1 (ref.) & \\
\hline & Male & $11.07(6.30)$ & $0.98(0.88-1.09)$ & 0.66 \\
\hline & Month & & & \\
\hline & March & $3.45(0.3)$ & 1 (ref.) & \\
\hline & April & $1.01(0.01)$ & $0.30(0.15-0.61)$ & $<0.01$ \\
\hline & May & $2.73(0.03)$ & $0.79(0.53-1.18)$ & 0.25 \\
\hline & June & $15.86(0.02)$ & $5.27(3.73-7.46)$ & $<0.01$ \\
\hline \multirow[t]{8}{*}{$21-60$} & Sex & & & \\
\hline & Female & $12.89(7.37)$ & 1 (ref.) & \\
\hline & Male & $14.41(7.79)$ & $1.10(1.06-1.13)$ & $<0.01$ \\
\hline & Month & & & \\
\hline & March & $4.03(0.19)$ & 1 (ref.) & \\
\hline & April & $2.38(0.11)$ & $0.58(0.49-0.69)$ & $<0.01$ \\
\hline & May & $3.79(0.17)$ & $0.94(0.84-1.06)$ & 0.31 \\
\hline & June & $19.30(0.75)$ & $5.69(3.16-6.29)$ & $<0.01$ \\
\hline \multirow[t]{8}{*}{$>60$} & Sex & & & \\
\hline & Female & $9.10(6.34)$ & 1 (ref.) & \\
\hline & Male & $9.42(6.52)$ & $1.03(0.94-1.13)$ & 0.46 \\
\hline & Month & & & \\
\hline & March & $5.42(0.08)$ & 1 (ref.) & \\
\hline & April & $1.95(0.03)$ & $0.35(0.24-0.51)$ & $<0.01$ \\
\hline & May & $2.15(0.04)$ & $0.38(0.29-0.51)$ & $<0.01$ \\
\hline & June & $15.31(0.02)$ & $3.15(2.49-3.99)$ & $<0.01$ \\
\hline
\end{tabular}

\section{Discussion}

This analysis showed that the AR of SARS-CoV-2 infection increased rapidly from 3.3\% (March - May) to 18.3\% (June) after lockdown was eased to level 3. Although the number of tests increased in June, the magnitude of the spread is reflected in the increase in the ARs across all age groups (Table 2). The infectivity respite during the lockdown created an opportunity for healthcare planning and preparation. The 'hard' level 5 lockdown may merely have delayed the surge of infection observed during subsequent levels.

It is likely that the drastic lockdown measures created an awareness of the gravity of SARS-CoV-2, thus facilitating implementation of non-pharmaceutical interventions. ${ }^{[7,8]} \mathrm{A}$ disproportionate number of tests were performed in the different age groups. After weighting for age and gender, a similar trend in AR was noted (Fig. 3).

The age group $21-60$ years represents the population that returned to work and constituted $83.2 \%$ of positive cases in our study. This age group represents $\sim 61 \%$ (9.4 million) of the Gauteng population $^{[6]}$ and accounted for $\sim 40 \%$ of SARS-CoV- 2 mortality in the province as of July $2020 .{ }^{[9]}$ Age analyses of countries such as Spain, Germany, the UK and Italy indicate that $\sim 60-70 \%$ of SARS-CoV-2-positive individuals fell into the 20 - 60-year age category. ${ }^{[10-13]}$ The increase in the AR in this age group during level 3 lockdown in June may have been influenced by factors such as cluster transport, workforce migration, workplace interaction, cluster living, and lack of adaptability to the mitigation measures. These factors could have contributed to an increase in the AR with easing of lockdown in the province. This increase in the AR indicates failure to consolidate the gains achieved during the lockdown, including stringent implementation of infection prevention and control (IPC) measures in the workplace and social spaces. The rising infectivity and mortality rates in this age group will have dire social and economic consequences, which will adversely affect households. It is therefore important to increase our efforts in implementing effective IPC strategies in workplace and social spaces.

The age group 0 - 20 years represents school attendees. This age group comprises 30\% (4.7 million) of the Gauteng provincial population $^{[6]}$ and accounted for $\sim 1 \%$ of SARS-CoV-2 mortality in the province as of July $2020 .{ }^{[9]}$ The exponential increase in the AR in our study (15.9\%) during June in comparison with $2.7 \%$ (prelevel 3 lockdown) confirms the global consensus that restricting outdoor activities in children slowed the transmission rate ${ }^{[14]}$ and contradicts current opinion about susceptibility to infection. ${ }^{[15,16]}$ In the townships, outdoor activities for children were likely to have been restricted during level 5 and the ease in lockdown may have aggravated the situation. This age group also includes subsets of students attending high schools as well as higher educational institutions. Intergenerational exposure at home (cluster living) and outdoors is likely to contribute to the upsurge and should be taken into consideration when making future decisions regarding exposure to social excursions, outdoor activities, and opening of educational facilities in the province.

The age group $>60$ years represents a group with high rates of comorbidities and that in which SARS-CoV-2 mortality is likely to be highest. A significant number of these individuals are likely to be retired or pensioners. More than $20 \%$ of the population in developed countries such as Spain, Germany, the UK and Italy is aged $>60$ years, ${ }^{[10-13]}$ compared with $8.4 \%$ in Gauteng. ${ }^{[6]}$ This group constituted a large number of infected cases $(n=1628)$ (Table 2), and the majority of them were detected in June $(n=1418)$. As expected, $\sim 57 \%$ of the SARS-CoV-2 mortality in Gauteng occurred in this age 
group. ${ }^{[9]}$ Targeted population strategies (dedicated screening, testing and treatment, continuation of critical services, home delivery of medication and pension allowances) should be employed to mitigate the morbidity and mortality in this high-risk age group.

In addition, in low-income communities, cluster living is unavoidable and preventive strategies (e.g. use of face masks and sanitisers) may not be a priority. In these communities, the development of natural 'herd immunity' is expected to ultimately curtail infectivity. Social and economic inequalities are relevant to the rate and extent of SARS-CoV-2 infectivity in communities. Affluent communities are likely to have better access to healthcare. In addition, non-pharmaceutical preventive strategies (face mask use, social distancing, sanitising, etc.) are easier to implement. It is therefore expected that lockdown measures may have a greater benefit in affluent communities. ${ }^{[17-19]}$

The low infectivity during level 5 lockdown provided an opportunity to prepare the healthcare infrastructure. However, the low incidence of COVID-19 during this time must be measured against the potential 'side-effects' of a hard lockdown. Malnutrition, lack of access to chronic medication, delayed presentation of illnesses and gender-based violence may all have contributed significantly to overall morbidity and mortality. The potential for excess deaths and 'net harm' as a result of the indirect impact of lockdown measures needs to be considered by policymakers. ${ }^{[20-24]}$

\section{Study limitations}

This study is based on retrospective analysis of secondary data from a private pathology laboratory. The findings may therefore not be generalisable. However, this laboratory covers all the districts in the province, and we analysed $40 \%$ of the positive cases in the province during the 4-month study period. We were also notified that a number of RT-PCR tests were requests made by National Health Laboratory Service. Anonymised data did not allow us to quantify these individuals. In addition, it is not clear to what extent the change to a more selective testing policy influenced requests made to private laboratories (and the high AR). It is our impression that private laboratories continued to test patients referred by doctors, and to some extent self-referred patients who claimed to have symptoms. Private hospitals also instituted policies of routine testing of all admitted patients irrespective of symptoms.

\section{Conclusions}

While the imposed lockdown slowed down viral transmission, the economic and financial trade-off was non-sustainable. Preservation of the economy is largely dependent on the $20-60$-year age group. The age groups $<20$ and $>60$ years jointly comprise $40 \%$ of the Gauteng population. Our data indicate that both these groups contribute significantly to the AR and infectivity. Balancing lockdown regulations with ongoing economic activity using age and geography as discriminators needs careful consideration.

The relatively low number of tests done in the age groups $0-20$ and $>60$ years is a concern in view of the findings of this study and would require further attention.

\section{Declaration. None.}

Acknowledgements. The authors wish to express their appreciation to Dr P Cole and his staff from Lancet Laboratories. Analysis of these valuable data has improved our understanding of SARS-CoV-2 transmission dynamics.

Author contributions. All the authors contributed to the preparation of the manuscript.

Funding. None.

Conflicts of interest. None.

1. Hamid S, Mir MY, Rohela GK. Novel coronavirus disease (COVID-19): A pandemic (epidemiology, pathogenesis and potential therapeutics). New Microbes New Infect 2020;35:100679. https://dol org/10.1016/j.nmni.2020.100679

2. National Institute of Communicable Diseases. First case of COVID-19 reported in South Africa. 5 March 2020. https://www.nicd.ac.za/first-case-of-covid-19-coronavirus-reported-in-sa/ (accessed 28 July 2020).

3. South Africa. Disaster Management Act, 2002: Regulations relating to COVID-19. Government Gazette South Africa. Disaster Management Act, 2002: Regulations relating to COVID-19. Government Gazette
No. 43107, 18 March 2020. (Published under Government Notice 318.) https://www.saps.gov.za/ No. 43107, 18 March 2020. (Published under Government Notice
newsroom/convid_regulations_2020.pdf (accessed 28 August 2020).

newsroom/convid_regulations_2020.pdf (accessed 28 August 2020).
4. National Department of Health, South Africa. Stages of lock down. https://www.gov.za/covid-19/about/ about-alert-system (accessed 28 July 2020).

5. South African Government. Minister Zweli Mkhize confirms total of 159333 cases of Coronavirus COVID-19. 1 July 2020. https://www.gov.za/speeches/minister-Zweli-mkhize-confirms-total-159-333cases-coronavirus-covid-19-1-jul-2020-0000 (accessed 28 July 2020).

6. Statistics South Africa Mid-year population estimates. Pretoria: Stats SA, 2020. http://www.statssa.gov.za/ publications (accessed 27 July 2020).

Flaxman S, Swapnil M, Axel G, et al. Estimating the effects of non-pharmaceutical interventions on COVID-19 in Europe. Nature 2020;584:257-261. https://doi.org/10.1038/s41586-020-2405-7

8. Garcia LP, Duarte E. Non-pharmaceutical interventions for tackling the COVID-19 epidemic in Brazil. Epidemiol Serv Saude 2020:29(2):e2020222 https://doi.org/10.5123/s1679-49742020000200009

9. Businesstech. New Gauteng Covid-19 data reveals deaths by age in South Africa’s epicentre. 17 July 2020. 9. Businesstech. New Gauteng Covid-19 data reveals deaths by age in South Africa's epicentre. 17 July 2020.
https://businesstech.co.za/news/government/417505/new-gauteng-covid-19-data-reveals-deaths-byhttps://businesstech.co.za/news/government/417505/n

10. Statista Research Department. Coronavirus: Age of patients in France. 2020. https://www.statista.com/
(a) . Statista Research Department. Coronavirus: Age of patients in France. 2020.
statistics/1102881/infections-coronavirus-age-france (accessed 28 July 2020).

11. Thomala LL. Age distribution of COVID-19 patients in China. Statista, 6 April 2020. https://www. statista.com/statistics/1095024/china-age-distribution-of-wuhan-coronavirus-covid-19-patients (accessed 28 July 2020).

12. Stewart C. Coronavirus cases in England by age and gender. Statista, 16 September 2020. https://www statista.com/statistics/1115083/coronavirus-cases-in-england-by-age-and-gender (accessed 28 July 2020).

13. Statista Research Department. Distribution of coronavirus cases in Italy as of July 14,2020 by age group. 2020. https://www.statista.com/statistics/1106367/coronavirus-deaths-distribution-by-age-group-ital (accessed 28 July 2020).

4. Lee PI, Hu YL, Chen PY, et al. Are children less susceptible to COVID-19? J Microbiol Immunol Infect 2020;53(3):371-372. https://doi.org/10.1016/j.jmii.2020.02.011

15. Wei M, Yuan J, Liu Y, et al. Novel coronavirus infection in hospitalized infants under 1 year of age in China. JAMA 2020;323(13):1313-1314. https://doi.org/10.1001/jama.2020.2131 16. Shima E, Tariq A, Cho W, et al. Transmission potential and severity of COVID-19 in South Korea. Int J
Infect Dis 2020;93:339-344. https://doi.org/10.1016/j.ijid.2020.03.031

17. Anderson G, Frank JW, Naylor CD, Wodchis W, Feng P. Using socioeconomics to counter health disparities arising from the covid-19 pandemic. BMJ 2020;369:m2149. https://doi.org/10.1136/bmj. $\mathrm{m} 2149$

18. Gathright J. Study finds significant racial, socioeconomic disparities in COVID-19 among children. NPR, 7 August 2020. https://www.npr.org/local/305/2020/08/07/900166845/study-finds-significant-racialsocioeconomic-disparities-in-c-o-v-i-d-19-among-children (accessed 7 September 2020).

19. Myers J. 5 things COVID-19 has taught us about inequality. World Economic Forum COVID Action Platform, 18 August 2020. https://www.weforum.org/agenda/2020/08/5-things-covid-19-has-taught-usabout-inequality/ (accessed 7 September 2020).

20. Duarah RG. Side effect of corona and lockdown. The Hills Times, 29 May 2020. https://www.thehillstimes. in/featured/side-effect-of-corona-and-lockdown/ (accessed 7 September 2020).

21. Alzheimer's Society. Lockdown's side effect: Mental health deterioration of people affected by dementia, with third 'giving up'. 14 July 2020. https://www.alzheimers.org.uk/news/2020-07-14/lockdowns-sidewith third giving up. 14 July 2020. https://www.alzheimers.org.uk/news/2020-07-14/lockdown
effect-mental-health-deterioration-people-affected-dementia-third (accessed 7 September 2020).

22. Rigby J. Is the cure worse than the disease? The hidden harms of Covid-19 lockdowns. The Telegraph, 5 June 2020. https://www.telegraph.co.uk/global-health/science-and-disease/cure-worse-diseasehidden-harms-covid-19-lockdowns/ (accessed 7 September 2020).

23. Lee J. Covid's metamorphosis: Has lockdown made the virus more deadly? The Spectator, 2 May 2020 https://www.spectator.co.uk/article/covids-metamorphosis-has-lockdown-made-the-virus-more-deadly (accessed 7 September 2020).

24. Jonah C, May J, Sambu W. Lockdowns threaten children's nutrition: Why extra care is needed. The Conversation, 13 April 2020. https://theconversation.com/lockdowns-threaten-childrens-nutrition-whyextra-care-is-needed-135837 (accessed 7 September 2020).

Accepted 15 September 2020. 